\title{
La protección de adultos: notas desde el Derecho Internacional Privado argentino
}

\section{POR LUCIANA B. SCOTTI(*) Y LEANDRO BALTAR(**)}

\begin{abstract}
Sumario: I. Introducción.- II. La protección de los adultos. Alcances.III. La protección internacional de adultos en clave de Derechos Humanos.- IV. Aportes del Derecho Internacional Privado para la protección de adultos.- V. El Convenio de La Haya sobre protección internacional de adultos de 2000.- VI. Notas desde el Derecho Internacional Privado argentino.- VII. Observaciones finales.- VIII. Bibliografía.
\end{abstract}

Resumen: la protección de las personas adultas es un tema históricamente desatendido por el derecho. Pudiendo ser estudiado desde varias materias, el Derecho Internacional Privado es capaz de brindarle una gran cantidad de herramientas. Desde la mirada argentina, la inexistencia de normas especiales tanto de fuente interna como convencional que aborden adecuadamente la protección de estos sujetos se traduce en una falta de atención jurídica internacional, poniéndolos en un estado de indefensión. En la actualidad, todo el derecho se encuentra ante un reto particular: la necesidad de protegerlos mediante normas justas. En el presente trabajo, abordaremos el tema desde la mirada y aportes del Derecho Internacional Privado para reforzar su protección.

(*) Abogada, egresada con Medalla de Oro (UBA). Magister en Relaciones Internacionales (UBA). Dra. de la Universidad de Buenos Aires con tesis sobresaliente, recomendada al Premio "Facultad" (Área Derecho Internacional). Diploma de Posdoctorado, Facultad de Derecho, Universidad de Buenos Aires (UBA). Prof. Adjunta regular Derecho Internacional Privado y Derecho de la Integración, Facultad de Derecho (UBA). Dir. de la Revista Iberoamericana de Derecho Internacional y de la Integración. Vicedirectora e investigadora formada del Instituto de Investigaciones Jurídicas y Sociales "Dr. Ambrosio L. Gioja", Facultad de Derecho, Universidad de Buenos Aires. Autora y coautora de libros, capítulos de libros, artículos, ponencias y comunicaciones en Congresos, sobre temas de su especialidad.

(**) Abogado. Magíster en Derecho Internacional Privado, Universidad de Buenos Aires (UBA). Doctorando en Derecho Internacional, Universidad de Buenos Aires (UBA). Prof. Derecho Internacional Privado y Derecho de la Integración, Facultad de Derecho, Universidad de Buenos Aires. Becario Doctoral UBACyT. Coord. de la Revista Iberoamericana de Derecho Internacional y de la Integración. Miembro adscripto del Instituto de Investigaciones Jurídicas y Sociales "Dr. Ambrosio L. Gioja”, Facultad de Derecho, Universidad de Buenos Aires. Autor y coautor de artículos y capítulos de libros sobre temas de su especialidad. 
Palabras claves: Derecho Internacional Privado - protección de adultos jurisdicción - derecho aplicable - cooperación internacional

\section{The protection of adults: notes from argentine private international law}

Abstract: the protection of the adults is an issue historically neglected by law. Being able to be studied from various subjects, Private International Law is characterized by being able to provide a large number of tools. From the Argentine point of view, the lack of special norms from both internal and conventional sources that adequately address the protection of these subjects translates into a lack of international legal attention, putting them in a state of defenselessness. Today, the law is faced with a particular challenge: the need to protect them through fair rules. In this work, we will approach the issue from the perspective and contributions to reinforce its protection from Private International Law.

Keywords: International Private Law-Adult protection - Jurisdiction - Applicable law - International cooperation

\section{Introducción}

En un mundo caracterizado por una creciente movilidad geográfica, la cual impacta en las relaciones jurídicas al internacionalizarlas, aparecen incesantes dificultades que afectan a todas las personas. En este sentido, la libertad de circulación impulsada por los espacios de integración incrementa esta circunstancia generando que el Derecho Internacional Privado (DIPr) se interese en su regulación al afectar todos sus sectores.

Cuando este movimiento transfronterizo comprende a personas adultas vulnerables, por su situación de desamparo y el riesgo en su seguridad, se pone de evidencia la necesidad de adoptar medidas destinadas a protegerlos. Surgen en este punto las clásicas preguntas de nuestra disciplina: ¿cuáles son las autoridades ante las cuales peticionar alguna medida de protección?; ¿ cuál será el derecho aplicable a ellas y a estos sujetos? El sistema de protección requiere de herramientas distintas y específicas que de manera eficaz puedan cumplir con ese cometido. $\mathrm{Al}$ intentar responder estos interrogantes ya puede comenzar a concluirse la necesidad de contar con disposiciones que logren armonizar las normas junto a la creación de un amplio sistema de cooperación.

A diferencia de lo que sucede con la protección internacional de los niños, niñas y adolescentes, la cual goza desde hace unos cuantos años de un reconocimiento a nivel mundial con un gran impacto en las normativas de todos los Estados quienes entendieron su importancia al ratificar convenios de amplia perspectiva, en materia de adultos el camino se caracteriza por una mayor lentitud, a 
pesar de su innegable importancia (Álvarez Torne, 2016, p. 2). Aún en un espacio tan progresista en brindar soluciones modernas al DIPr como lo es la Conferencia de La Haya, el trabajo realizado en protección de adultos no puede compararse con los logros respecto del cuidado de la infancia, pero no por ello es inexistente (Lagarde, 2017, p. 41).

Desde una mirada general, puede afirmarse que no existe en Argentina una normativa que aborde e instaure adecuadamente una protección específica que las personas adultas merecen. Al menos, no como corresponde. Ello no implica negar la existencia de normas aplicables. Esta situación es compartida, es decir, no es una dolencia única de nuestro país. Puede verse, a modo de ejemplo, como en la reciente Ley General de Derecho Internacional Privado de Uruguay (19.920, aprobada en diciembre de 2020) así como en el Anteproyecto de Ley de Derecho Internacional Privado presentado al ministro de Justicia de Chile (22 septiembre 2020) se padece de una situación similar. Es muy factible, entonces, que las medidas adoptadas en un país puedan no ser reconocidas en otro, o sea muy arduo el camino para su reconocimiento. En tal sentido, se entiende que: "El cruce de la frontera puede conllevar un cambio de ley aplicable, ley que puede ser incompatible con las medidas adoptadas previamente" (Muñoz Fernández, 2020, p. 1101). Este es tan solo uno de los problemas que pueden despertarse.

Si bien existe una protección desde el Derecho Internacional de los Derechos Humanos, no resulta suficiente y es en ese punto donde encontramos una amplia laguna normativa. En efecto, no puede desconocerse la vigencia de tratados de Derechos Humanos que instauran principios fundamentales, pero se requiere una regulación específica para así garantizar el disfrute de sus derechos: son sujetos a proteger en lo relativo a su cuidado personal como a la administración de su patrimonio y allí los DDHH solo instauran principios y directrices encaminadas hacia los Estados.

La preocupación por este sector de la población viene despertando interés desde hace varios años. Ello impactó en el DIPr generando un cambio de paradigma: la percepción sobre los adultos vulnerables se trasladó de ser considerados únicamente como receptores de cuidados a ser verdaderos titulares de derechos (Franzina, 2016, p. 129). En busca de esta finalidad, se conforma el llamado "sistema de protección de las personas adultas", el cual tiende a establecer una serie de normas y principios que busca protegerlos por su condición de especial vulnerabilidad. Encarar la creación y desarrollo de este sistema es un deber porque estamos ante sujetos que presentan una debilidad jurídica inherente a su condición: implica estar ante personas que, ya sea por una disminución o por una insuficiencia de sus facultades, no están posibilitados de velar por sí mismos para proteger sus intereses. De estarlo, se debería acudir a las normas propias para la materia regulada. Esta especialidad innata los hace merecedores de disposiciones autónomas. 
La escasa regulación en materia de protección de adultos a nivel internacional junto a la insuficiente normativa vigente en el Código Civil y Comercial de la Nación (CCiv. y Com.) se presenta como un terreno fértil. Estamos hablando de una categoría poco explorada en el DIPr, lo cual nos llevará en muchos casos a teorizar sin contar con soluciones normativas o jurisprudenciales concretas.

\section{La protección de los adultos. Alcances}

Encontramos una clara tendencia en el derecho comparado - y muy especialmente en el derecho europeo- hacia la implementación y desarrollo de un sistema de protección de adultos. En los últimos años, y como consecuencia misma de la globalización y la multiculturalidad, se intenta flexibilizar la regulación en pos de buscar medidas que mejoren su tutela y protección.

En primer término, debemos preguntarnos cuáles son los "adultos" a los que nos referimos y sobre quienes alcanzará la protección. Esto implica abordar la problemática llamada "calificaciones". Una definición en este sentido es sumamente compleja, pues ya el mal uso de la terminología puede llevarnos a un camino erróneo por el impacto que pueden ocasionar. Es por ello que hay cierta preferencia en dejar de utilizar palabras como "discapacitados" (1), "deficientes", "incapacitados" o "minusválidos". Determinar, entonces, el alcance de lo que debe entenderse por "adultos vulnerables" se vuelve primordial, pues ello afecta el reconocimiento y alcance de las medidas de protección.

Partiendo del término "adulto", entendemos que nos referimos a todo sujeto que haya alcanzado la mayoría de edad. Para determinar cuándo ello sucede, es decir, determinar a qué edad las personas son adultas, consideramos correcto acudir a las normas que cada país posee para determinar la capacidad, en nuestro caso, será el derecho del domicilio de la persona de quien se trate (artículo 2616 Cod. Civ. y Com.).

En cuanto al alcance, es decir, determinar a qué sujetos mayores de edad esta protección abarca, no cabe duda que se incluye a quienes transiten o padezcan una disminución o insuficiencia de sus facultades personales, sea permanente o temporal, no pudiendo proteger sus intereses por sí mismos. Sobre ellos, en mayor o menor medida, todos los países reconocen algún tipo de figura destinada a crear un marco protector para garantizarle el respeto y cuidado de sus derechos. La dificultad la transitaremos en otros sujetos que atraviesen alguna compleja situación que requiera de una protección, debiendo determinarse si deben o no incluirse.

(1) Sin embargo, los convenios de Derechos Humanos tanto a nivel universal como interamericano han optado por el término "discapacidad". 


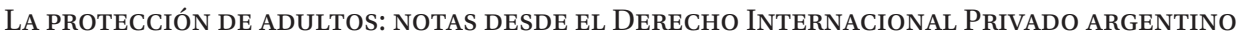
- LUCIANA B. SCOTTI Y LEANDRo BALTAR (PP. 427-456)

Recordemos que la cultura, las costumbres, el género, los valores y principios difieren según la ubicación geográfica y la legislación que analicemos.

Un ejemplo sobre el cual no podemos explayarnos por merecer de un autónomo tratamiento, pero nos permite visualizar de manera clara y directa esta problemática, es la situación de las personas - generalmente mujeres- sometidas a algún tipo de violencia transfronteriza. ¿Deben incluirse dentro de este "sistema de protección de adultos"? El mundo actual se encuentra transitando un camino dónde la violencia y el género específicamente está tomando un papel relevante y notorio. Si bien las medidas aún no son suficientes, pues siguen siendo de público conocimiento la cantidad de hechos y actos de violencia que se repiten, no puede negarse que es un tema sobre la mesa y en debate.

Generalmente, la escasa regulación existente excluye a este tipo de casos. En este sentido, Lagarde explica que el Convenio de La Haya del 2000 sobre Protección Internacional de Adultos no se aplica a supuestos de violencia externa, pues la protección requiere de medidas policiales, en el sentido usual y no técnico del término, y no medidas jurídicas de protección (Lagarde, 2017, párr. 9). En similar sintonía se encuentran aquellos casos en los cuales la vulnerabilidad proviene de la prodigalidad, del uso de estupefacientes o del abuso del alcohol. Según el Informe Explicativo del CLH 2000, estas vulnerabilidades también quedan fuera del ámbito de aplicación de la Convención, pues la "alteración o insuficiencia de las facultades personales" a la que se refiere el artículo 1 parágrafo 1 debe interpretarse como una "enfermedad" (Lagarde, 2017, párr. 9).

Esta idea puede resultar contraproducente. Entendemos que el correcto camino es estar a favor de una idea amplia de la vulnerabilidad y, como consecuencia, de las medidas de protección que sobre ellos puedan decretarse. Si tenemos como meta el cuidado del interés del adulto, y buscamos protegerlos jurídicamente, se debería focalizar en los efectos y no en la causa que motiva la protección, de allí que podría ampliarse su ámbito.

Bajo esta idea es que logra superarse aquella errónea concepción según la cual la incapacidad jurídica es el único modo o herramienta de protección de un adulto vulnerable, tal como podía concluirse con lo normado por el Código Civil argentino derogado y de sus pares decimonónicos. Como sucede en el derecho local, existen otras medidas destinadas a proteger y ayudar a las personas sin desencadenar en la incapacidad por sentencia judicial. Nos referimos, como ejemplo, a la situación jurídica del inhabilitado respecto a quien se mantiene la capacidad y se consolida la figura del "apoyo" (artículo 32 CCiv. y Com.), el cual, a diferencia del curador, no representa al inhabilitado ni puede actuar en su nombre, pero cuenta con la importante función de asistirlo, integrando con su conformidad la manifestación de la voluntad del propio inhabilitado (Borda, 2017, p. 275). 
Sumado a ello, dentro de esta categoría general podemos - y debemos- destacar un subgrupo que por su particular situación merecen de una especial mención: nos referimos al caso de las personas "adultas mayores". Esta distinción radica debido a que en los últimos años viene tomando un impulso el fenómeno llamado "gerontoinmigración", entendida como la movilidad transfronteriza de las personas mayores, quienes, al alcanzar la edad de jubilación y por razones de índole personal, deciden pasar la etapa final de su vida en otro país. Estando ante un grupo de la población con una gran incidencia en transitar algún tipo de trastorno, patología o enfermedad, se requiere de una mayor necesidad de crear normas que les garanticen la protección sin que la internacionalidad afecte sus derechos. Es por esta razón que se reconoce a esta población como un grupo aún más vulnerable sin ningún instrumento jurídico adaptado a sus necesidades particulares.

Como modo de enfrentar esta conflictiva solución, los Estados deben asumir la tarea de adaptar sus políticas sociales, económicas y jurídicas, especialmente en el ámbito de la seguridad social. Más allá del alcance que se le dé a la protección, de la terminología que se prefiera usar, lo cierto es que la vulnerabilidad implica que la persona se encuentra especialmente expuesta a sufrir daños o a ver lesionado sus derechos. Ante ello, todos los países están obligados a adoptar las medidas pertinentes para garantizárselos.

En definitiva, la noción de vulnerabilidad para definir la categoría de persona que nos ocupa en esta oportunidad es de suma importancia. Si bien no es, en principio, una noción jurídica, en los últimos años, podemos encontrar este concepto tanto en los sistemas nacionales como en los trasnacionales, tanto en el soft law como en el derecho positivo, bajo la orientación de las Reglas de Brasilia de Acceso a Justicia para Personas en Condición de Vulnerabilidad, aprobadas en la XIV Cumbre Judicial Iberoamericana realizada en Brasilia en marzo de 2008.

Nos quedamos, entonces, con la muy ilustrativa definición que brinda el Prof. Hughes Fulchiron: "Vulnus, vulneris, etimológicamente, el término vulnerabilidad viene de una palabra latina, que significa herida, herida del cuerpo o herida del espíritu. La persona vulnerable es aquella que puede ser herida, atacada o afectada. La vulnerabilidad reenvía a la idea de fragilidad y de debilidad; ella apela a la necesidad de protección de cuidado y de atención" (2017, p. 3).

\section{La protección internacional de adultos en clave de Derechos Humanos}

En la actualidad pueden encontrarse varios instrumentos internacionales de fuerte naturaleza pública en los cuales se reconocen Derechos Humanos fundamentales para todas las personas. Estos resultan claramente aplicables a los 


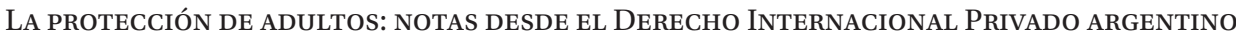

- LUCIANA B. SCOTTI Y LEANDRO BALTAR (PP. 427-456)

adultos en situación de vulnerabilidad. Pero además existen instrumentos internacionales específicos que ameritan una mención especial.

En primer lugar, por orden cronológico, la Convención Interamericana para la Eliminación de Todas las Formas de Discriminación contra las Personas con Discapacidad (Guatemala, 1999), aprobaba por ley 25.280, ratificada el 10 de enero de 2001, y en vigor desde el 14 de septiembre de 2001, define "discapacidad" como una deficiencia física, mental o sensorial, ya sea de naturaleza permanente o temporal, que limita la capacidad de ejercer una o más actividades esenciales de la vida diaria, que puede ser causada o agravada por el entorno económico y social. En tanto que "discriminación contra las personas con discapacidad", en los términos de la Convención, significa toda distinción, exclusión o restricción basada en una discapacidad, antecedente de discapacidad, consecuencia de discapacidad anterior o percepción de una discapacidad presente o pasada, que tenga el efecto o propósito de impedir o anular el reconocimiento, goce o ejercicio por parte de las personas con discapacidad, de sus derechos humanos y libertades fundamentales (artículo I).

De acuerdo con su texto los Estados partes se comprometen a la adopción de una serie de medidas con los objetivos de prevenir y eliminar todas las formas de discriminación contra las personas con discapacidad y propiciar su plena integración en la sociedad.

En el plano universal, contamos con la Convención sobre los Derechos de las Personas con Discapacidad, y con su Protocolo Facultativo, celebrados en Nueva York el 13 de diciembre de 2006, bajo auspicios de la Organización de Naciones Unidas. La República Argentina aprobó ambos instrumentos por ley 26.378, y los ratificó el 2 de septiembre de 2008, encontrándose en vigor desde el $1^{\circ}$ de octubre del mismo año. La Convención goza de jerarquía constitucional por ley 27.044, sancionada el 19 de noviembre de 2014.

El propósito de esta Convención es promover, proteger y asegurar el goce pleno y en condiciones de igualdad de todos los derechos humanos y libertades fundamentales por todas las personas con discapacidad, y promover el respeto de su dignidad inherente (artículo 1, inciso 1). Se basa en ocho principios rectores: 1) El respeto de la dignidad inherente, la autonomía individual, incluida la libertad de tomar las propias decisiones, y la independencia de las personas; 2) La no discriminación; 3) La participación e inclusión plenas y efectivas en la sociedad; 4) El respeto por la diferencia y la aceptación de las personas con discapacidad como parte de la diversidad y la condición humanas; 5) La igualdad de oportunidades; 6) La accesibilidad; 7) La igualdad entre el hombre y la mujer; y 8) El respeto a la evolución de las facultades de los niños y las niñas con discapacidad y de su derecho a preservar su identidad. 
Por otro lado, más recientemente, la Convención Interamericana sobre la Protección de los Derechos Humanos de las Personas Mayores (2), de 2015, fue aprobada por ley 27.360, ratificada en octubre de 2017, y se encuentra en vigor desde el 22 de noviembre de ese mismo año.

Este tratado menciona en su Preámbulo como antecedentes relevantes a: los Principios de las Naciones Unidas en favor de las Personas de Edad (1991); la Proclamación sobre el Envejecimiento (1992); la Declaración Política y el Plan de Acción Internacional de Madrid sobre el Envejecimiento (2002), así como los instrumentos regionales tales como la Estrategia Regional de implementación para América Latina y el Caribe del Plan de Acción Internacional de Madrid sobre el Envejecimiento (2003); la Declaración de Brasilia (2007), el Plan de Acción de la Organización Panamericana de la Salud sobre la salud de las personas mayores, incluido el envejecimiento activo y saludable (2009), la Declaración de Compromiso de Puerto España (2009) y la Carta de San José sobre los derechos de las personas mayores de América Latina y el Caribe (2012).

Su objetivo es promover, proteger y asegurar el reconocimiento y el pleno goce y ejercicio, en condiciones de igualdad, de todos los derechos humanos y libertades fundamentales de la persona mayor, a fin de contribuir a su plena inclusión, integración y participación en la sociedad. Debe destacarse que, al momento de establecer las definiciones, el convenio entiende por persona mayor a aquella que alcance los 60 años o más, salvo que la ley interna determine una edad base menor o mayor, siempre que esta no sea superior a los 65 años.

Sobre la base de este convenio, y con el fin de proteger a los adultos, corresponde a todos los Estados revisar su ordenamiento jurídico para así adoptar las medidas legislativas o de otro carácter que fueren necesarias para hacer efectivos tales derechos y libertades.

Por último, en el plano del soft law, merecen una referencia aparte las Reglas de Brasilia de Acceso a la Justicia para Personas en Condición de Vulnerabilidad, ya mencionadas, que constituyen un conjunto de disposiciones (100 reglas) que consagran los estándares básicos para garantizar el acceso a la justicia de las personas en condición de vulnerabilidad.

En Argentina fueron incorporadas por la Acordada 5-2009 de la Corte Suprema de Justicia de la Nación.

(2) En el sistema de protección africano, existe un tratado equivalente: el Protocolo de la Carta Africana de Derechos Humanos y de los Pueblos sobre los Derechos de las Personas Mayores adoptado en enero de 2016. 


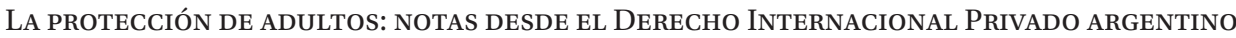

- LUCIANA B. SCOTTI Y LEANDRO BALTAR (PP. 427-456)

De acuerdo con ellas:

Se consideran en condición de vulnerabilidad aquellas personas que, por razón de su edad, género, estado físico o mental, o por circunstancias sociales, económicas, étnicas y/o culturales, encuentran especiales dificultades para ejercitar con plenitud ante el sistema de justicia los derechos reconocidos por el ordenamiento jurídico. Podrán constituir causas de vulnerabilidad, entre otras, las siguientes: la edad, la discapacidad, la pertenencia a comunidades indígenas o a minorías, la victimización, la migración y el desplazamiento interno, la pobreza, el género y la privación de libertad. La concreta determinación de las personas en condición de vulnerabilidad en cada país dependerá de sus características específicas, o incluso de su nivel de desarrollo social y económico.

Ahora bien, como puede notarse, todos los instrumentos mencionados son esencialmente de naturaleza pública y por ello carecen de disposiciones de DIPr destinadas a abordar sus sectores. Desde la mirada de nuestra disciplina, solamente podemos referirnos al Convenio de La Haya de 2000 sobre Protección Internacional de Adultos, no vigente en Argentina, sobre el que volveremos en detalle más adelante.

\section{Aportes del Derecho Internacional Privado para la protección de adultos}

El verdadero reto se presenta en el supuesto de la persona adulta vulnerable inserta en una relación jurídica transfronteriza que necesita de un marco jurídico internacional de protección adecuado. Desde el DIPr debemos centrarnos en solucionar el siguiente interrogante: ¿cómo un sistema jurídico moderno y respetuoso de los derechos humanos puede responder a la necesaria protección de los adultos en situación de vulnerabilidad? No escapa de la inteligencia del lector el modo en que los DDHH afectan de manera transversal todas las ramas del derecho. Nuestra materia no resulta una excepción. En efecto, y como sostiene Nadia de Araujo (2016) hoy son los encargados de aproximar al DIP y al DIPr, volviendo a unirlos donde estaban en conflicto.

\section{IV.1. En los sectores del DIPr}

Adoptando la postura que hace años venimos sosteniendo (Scotti, 2019), sabemos que el DIPr se compone de cuatro sectores: la determinación del derecho aplicable y de la jurisdicción internacional, la cooperación jurídica internacional y, finalmente, el reconocimiento y ejecución de sentencias (o laudos) extranjeros. 
La amplitud del objeto de esta materia permite nutrir y abordar todos los temas e institutos desde varias perspectivas las que, bien reguladas, convergen en un justo tratamiento normativo. $\mathrm{Al}$ menos, a esa meta siempre debemos aspirar.

Dentro del primer sector, surge el interrogante respecto del derecho que determinará las medidas judiciales (y extrajudiciales) que deban dictarse en un país en un caso con elementos extranjeros relevantes y la posibilidad de que gocen de un reconocimiento automático (o condicionado) en otro. En este punto, el pluralismo metodológico cumple un papel fundamental, analizaremos seguidamente este aporte.

La situación de vulnerabilidad intrínseca de estos sujetos es el argumento suficiente que justifica la necesidad de contar con normas de cooperación jurídica internacional destinadas a la protección y, al mismo tiempo, pueda garantizar el "interés del adulto" como principio fundamental, única forma de respetar su dignidad y voluntad.

El camino más efectivo para una cooperación fuerte y segura se lograría mediante la adopción de un tratado internacional. La unificación de normas especiales para esta temática junto al beneficio que gozaría la ubicación jerarquía que poseen los convenios en un número significativo de países impulsaría la protección efectiva de los adultos vulnerables que se encuentren en situaciones transfronterizas. Afirmar esto nos llevaría en gran medida a concluir por la adhesión al Convenio de La Haya. Pero vimos cómo - lamentablemente- no logró el éxito esperado. Consecuencia inmediata de ello es la necesidad imperiosa de suplir este vacío con normas internas que aborden de manera completa esta compleja temática. No son muchos los países que lograron modernizar sus legislaciones pudiendo de este modo tanto actualizar viejas soluciones y, en otros casos, receptar nuevas figuras. Incluso, algunos que llegaron a ese mérito, lo hicieron adoptando normas elaboradas muchos años atrás. Será importante revisar y analizar qué se encuentra regulado actualmente y, en caso de ausencia, tomar como punto de partida el Convenio de La Haya del 2000, adaptando las soluciones en caso de que sea necesario.

Por su lado, la disparidad de normas puede ocasionar otro problema: una medida de protección dictada por autoridades judiciales extranjeras puede verse difícilmente reconocida y/o ejecutada por colisionar con sistemas menos favorecedores o, cuando entre el país de origen y el de destino no haya similitudes en las normas. Argentina es el claro ejemplo de ello. El riguroso sistema de exequatur receptado en el Código Procesal Civil y Comercial de la Nación, el cual, lamentablemente, no pudo cambiarse en el CCiv. y Com., pese al intento de la Comisión redactora, dificulta los efectos en nuestro territorio de estas decisiones. La 


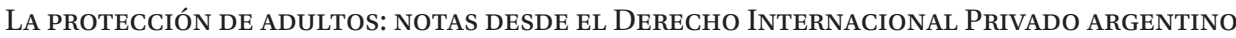

- LUCIANA B. SCOTTI Y LEANDRO BALTAR (PP. 427-456)

exigencia de la bilateralidad al momento de llevar adelante el control de competencia evidencia este extremo.

En palabras simples, receptar disposiciones desde los cuatro sectores del DIPr permitiría la eliminación de obstáculos y así contribuir a un adecuado funcionamiento hacia la protección internacional de los adultos vulnerables.

\section{IV.2. En el pluralismo metodológico}

En este aspecto, la importancia está centrada resolver la incertidumbre al momento de tener que determinar tanto el derecho conforme el cuál se decrete alguna medida de protección en caso de corresponder, como de la vigencia y efectos de ellas cuando son dictadas en un país sobre una persona adulta que cambia su residencia. Como destacamos, los problemas radican tanto en la ausencia normativa como en la diversidad de normas, generalmente indirectas, que desencadenan posibles incoherencias jurídicas. ¿Cómo regular y controlar este fenómeno?

El DIPr actual se caracteriza por la flexibilidad como un modo de escapar de la rigidez de las soluciones a las que se arribaría con la clásica norma conflictual, así lo han destacado, incluso, los Fundamentos del Anteproyecto de Código Civil y Comercial de 2012 (Scotti, 2020). De esta manera, y adaptado al tema de estudio, una buena opción sería la regulación a través de normas materialmente orientadas. Bajo esta modalidad, el principio "mayor interés del adulto" se utilizaría como directriz que mueva la balanza, se presenta como un modo de respetar y asegurar esta protección. Cumplir con esta orientación material implica que el juzgador tendrá en cuenta con especial ímpetu los intereses del sujeto especialmente vulnerable, buscando la solución acorde al derecho que más beneficie y proteja su vida.

Sin dudas, en temas sensibles donde entran en juego intereses y derechos de sujetos vulnerables, la protección se vería satisfactoriamente cumplida con mecanismos ya no tan rígidos.

Otra solución importante se centra en el "método de reconocimiento". Si bien se encuentra sometido a un profundo cuestionamiento por un sector de la doctrina (Lagarde, 2011), no puede negársele los beneficios susceptibles de brindar, especialmente en temas tan sensibles como el presente.

En efecto, las medidas tomadas en algún país por las cuales se establece algún tipo de protección sobre el adulto solo pueden producir efectos en otro territorio si logran pasar el proceso de reconocimiento de conformidad con lo establecido localmente en cada Estado. Solo de este modo se permite dentro de un territorio que actos administrativos o judiciales originados en otra nación puedan desarrollar las 
consecuencias jurídicas que de él se esperan. En países como Argentina, y sobre todo con la vigencia del CCiv. y Com., existe un deber jurídico en cooperar (artículo 2611 CCiv. y Com.) y en respetar las medidas jurisdiccionales dictadas en el extranjero siempre que cumplan con los requisitos exigidos. Más complicado sería en aquellos países aún receptores de la cortesía y la reciprocidad en los cuales el reconocimiento se daría por deferencia y respeto, no por obligación.

Como una forma de superar estas dificultades, y favorecer el reconocimiento de las medidas adoptadas para la protección, receptar el método de reconocimiento permitirá cristalizar esta situación jurídica y, siempre protegiendo los principios fundamentales, facilitar la producción de sus efectos fuera de las fronteras del país donde aquella fue dispuesta. En efecto, siguiendo este sistema se obtendrá el reconocimiento de pleno derecho, lo cual significa que no será necesario recurrir a ningún procedimiento especial para obtenerlo.

Un ejemplo que permite visualizar este supuesto se daría con los institutos regulados y admitidos en el extranjero, especialmente en Estados europeos como sucede con Suiza y la Ley de protección de adultos. Dicha normativa, que presupone como finalidad mejorar el derecho de autodeterminación de la persona (Schwenzer y Keller, 2013, p. 377), introdujo dos figuras: por un lado, el Vorsorgeauftrag, por el cual una persona con capacidad de obrar puede instruir a una persona física o jurídica para que asuma la responsabilidad de su cuidado personal o la gestión de sus activos o para que actúe como su apoderado legal en caso de que no sea más capaz de juzgar (artículo 360 Código Civil Suizo). Por el otro, se receptó la figura del Patientenverfilgung, una directiva anticipada de asistencia sanitaria (artículo 360 Código Civil Suizo) por la cual la persona declara los tratamientos médicos que consiente o no consiente en caso de incapacidad, siendo la Oficina del Registro Civil quien registrará el hecho de que una persona ha ejecutado una directiva de atención anticipada y el lugar donde se guarda. Similar situación podría pasar si lo que se invocase fuesen figuras como la autotutela o el patrimonio especialmente protegido reconocido por el derecho español. Imaginemos el supuesto dónde se invoque en Argentina alguno de estos institutos. Contar con disposiciones acorde a esta protección resolvería de manera óptima los problemas susceptibles de presentarse.

\section{IV.3. En los principios fundamentales}

El orden público internacional, entendido como el conjunto de principios fundamentales, es una de las herramientas de que se sirve el DIPr para descartar la aplicación de un derecho extranjero cuando aquellos se vean afectados (así como para desconocer los efectos de un acto o decisión extranjera). Determinar cuáles son los principios que lo integran es una tarea ardua pero no imposible. Como no 


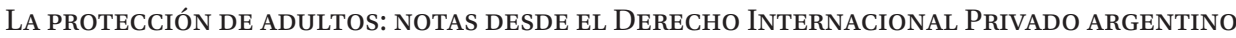

- LUCIANA B. SCOTTI Y LEANDRO BALTAR (PP. 427-456)

puede ser de otro modo, y como consecuencia de la dificultad en determinar su contenido, será labor de las autoridades judiciales analizar el caso en concreto para delimitar su alcance.

La base para poder determinarlos nos lleva a acudir a los DDHH, sobre todo por el rango constitucional que poseen en países como el nuestro. De allí la afirmación de que cumplen con una función catalizadora del orden público internacional.

Por ende, las normativas locales deberán siempre adecuarse de modo de garantizar estos principios fundamentales. Así, se entiende que "el diseño de las normas de DIPr relativas a la protección de adultos vulnerables debe de garantizar el respeto de los derechos humanos de los adultos incapaces" (Franzina, 2016, p. 138). Al mismo tiempo, este conjunto de principios que los conforman deberá siempre resguardarse cuando, al aplicar un derecho extranjero, sean susceptibles de ser lesionados.

Así como existe el principio del "interés superior del niño, niña o adolescente", podemos buscar su similar en nuestro tema, y hablar del respeto al "principio de mayor interés del adulto vulnerable". Como diferencia destacable entre ambos se denota que en materia de adultos lamentablemente no tiene un reconocimiento universal, lo cual vuelve complejo poder definirlo, incluso tampoco puede encontrarse una definición específica de él dentro del Convenio de La Haya. Por su parte, el informe explicativo del Prof. Lagarde tampoco proporciona ninguna directriz al respecto (Álvarez Torne, 2016, p. 8). Pese a ello, podemos concluir que permite crear un manto de protección vinculado especial y directamente con la dignidad que le corresponde, independientemente de la capacidad o incapacidad que posea. En este sentido, implicaría reconocer que el bienestar de la persona vulnerable prevalece tanto sobre el interés general del Estado en la armonía internacional de las decisiones como sobre los intereses de otros miembros de la familia (Long, 2013, p. 59).

Siguiendo la comparación con los avances realizados en el ámbito de la niñez, la protección de garantías procesales nos lleva a incluir como principio fundamental el derecho del adulto a ser oído en el procedimiento en el cual se discute su protección. También pueden considerarse como parte de tales principios: el respeto a su dignidad, la no discriminación, la plena participación e inclusión en la sociedad, la igualdad de oportunidades y la accesibilidad.

\section{El Convenio de La Haya sobre Protección Internacional de Adultos de 2000}

El Convenio celebrado el 13 de enero de 2000 en el ámbito de la Conferencia de La Haya sobre la Protección Internacional de Adultos aborda la jurisdicción 
competente, la ley aplicable, así como el reconocimiento y la ejecución de medidas. El Convenio también establece un mecanismo de cooperación entre las autoridades de los Estados partes.

La Conferencia de La Haya admite que este Convenio busca reforzar importantes obligaciones derivadas de la Convención de las Naciones Unidas sobre los Derechos de las Personas con Discapacidad, de 13 de diciembre de 2006, ya mencionada, incluidas las disposiciones de los artículos 12, sobre la igualdad de reconocimiento ante la ley, 18, sobre la libertad de circulación y nacionalidad, y 32, sobre la cooperación internacional.

En un análisis de su origen, explica Alegría Borrás Rodríguez que al inicio se pensó en regular el tema como un anexo al Convenio en materia de responsabilidad parental y de medidas de protección de los niños, pero la complejidad al armonizar las reglas para ambos temas por las notables diferencias, se optó por un tratamiento separado (2000, p. 5).

El convenio consta de 59 artículos y sigue los lineamentos y la estructura del Convenio de La Haya de 1996 sobre Responsabilidad de los Padres y Medidas para la Protección de los Niños pues fueron negociados prácticamente por los mismos expertos, pero se ha adaptado para satisfacer las necesidades específicas de los adultos vulnerables.

Tal como destaca el Prof. Lagarde, existen importantes diferencias entre la protección de niños y de adultos. En primer lugar, respecto a los primeros, lo esencial es la protección de la persona, en tanto que lo atinente a sus bienes es totalmente accesorio. Mientras que, respecto de los adultos, que suelen tener bienes, es igualmente importante el resguardo de su persona como de su patrimonio. Por otro lado, en el caso de los niños, nos encontramos en general con un conflicto entre sus padres o entre las familias de sus padres. El objetivo principal del Convenio de 1996 es evitar, en principio, la concurrencia de autoridades de distintos Estados para adoptar medidas de protección. Por el contrario, se procura concentrar la competencia en las autoridades del Estado de residencia habitual del niño. En el caso de los adultos, si bien es deseable que las autoridades de su residencia habitual se ocupen de las medidas para su protección, ello no siempre es posible. En estos supuestos, la concurrencia, evitada legítimamente en materia de niñez, puede resultar útil respecto a los adultos.

Otra diferencia relevante es que el niño es jurídicamente un incapaz, cuyos representantes son los padres que ejercen la responsabilidad parental. El adulto, en cambio, es capaz, dado que una medida de protección no necesariamente reduce ni suprime su capacidad. Precisamente, porque es capaz, puede lúcidamente prever y organizar anticipadamente su protección para cuando sea necesario. Esta 


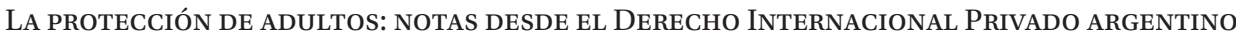

- LUCIANA B. SCOTTI Y LEANDRO BALTAR (PP. 427-456)

facultad, reconocida por muchas legislaciones, admite un cierto espacio para la autonomía de la voluntad.

Estas diferencias motivaron que las disposiciones en materia de jurisdicción competente y de derecho aplicable no estén calcadas, sino que presentan innovaciones significativas. Ello no sucede, en cambio, respecto a las disposiciones sobre cooperación entre autoridades de los Estados partes que son muy similares (Lagarde, 2000, p. 163).

El Convenio se aplica en situaciones internacionales, a "la protección de los adultos que, por razón de una alteración o insuficiencia de sus facultades personales, no están en condiciones de proteger sus intereses".

En el artículo 3 se enumeran los supuestos sobre los que pueden versar las medidas de protección, enumeración que no implica una limitación pues la propia norma dice "pueden referirse" denotándose una clara mención ilustrativa. Entre ellas se menciona la tutela, la curatela o instituciones similares, así como la posibilidad de poner a un adulto bajo la protección de una autoridad o en un centro especializado.

A diferencia de ello, en el artículo 4 se establece de manera taxativa las materias que se encuentran excluidas del convenio las cuales, como las explica Lagarde en el informe, deben entenderse de forma restrictiva (2017, p. 34).

El Convenio establece normas uniformes para determinar qué autoridades nacionales son competentes para adoptar las medidas de protección necesarias. Atribuye, en primer lugar, la competencia a las autoridades del lugar de residencia habitual del adulto. No obstante, la competencia de las autoridades del Estado del que el adulto es nacional, aunque concurrente, también se reconoce con carácter subsidiario. Además, puede reconocerse la competencia de las autoridades del Estado en el que se encuentran los bienes del adulto para adoptar medidas de protección respecto a ellos, así como la de las autoridades del Estado en el que se encuentra el adulto o sus bienes cuando se trata de adoptar medidas de emergencia o medidas temporales de eficacia territorial limitada para la protección de la persona. Por último, la posibilidad de que las autoridades competentes soliciten a las autoridades de otros Estados que adopten medidas de protección en interés del adulto proporciona aún más flexibilidad.

En general, al ejercer la jurisdicción en virtud del Convenio, las autoridades de los Estados partes aplicarán su derecho interno. Una excepción a la norma general sobre la ley aplicable se refiere a los poderes de representación. En los casos en los que un adulto ha hecho arreglos por adelantado para su cuidado y representación en caso de incapacidad, debe resolverse la cuestión de la validez de estos arreglos 
en el nuevo país de residencia. Según el Convenio, el adulto puede designar la ley aplicable a la existencia, alcance, modificación y extinción de los poderes ejercidos por una persona que lo represente. El adulto puede optar por designar la ley de: a) un Estado del que es nacional; b) el Estado en el que tenía su residencia habitual; o c) un Estado en cuyo territorio están situados sus bienes. De este modo, el Convenio garantiza el reconocimiento de un poder, un mandato de protección futura o acuerdos similares en otro Estado contratante, incluso cuando este último Estado no disponga de tales instituciones en su derecho interno. Esto le da al adulto la seguridad de que los arreglos que ha hecho para sus asuntos serán respetados en otros Estados contratantes.

Por otra parte, en virtud del Convenio, las medidas de protección de la persona o los bienes de un adulto, adoptadas en un Estado contratante serán reconocidas de pleno derecho en los demás Estados contratantes. Solo un número limitado de motivos puede servir de base para denegar el reconocimiento.

Al igual que otros convenios de La Haya, el Convenio de 2000 asigna un rol destacado a las disposiciones sobre la cooperación entre los Estados destinadas a mejorar la protección de los adultos vulnerables. Este sistema de cooperación incluye, entre otras cosas, el intercambio de información, la ayuda para encontrar soluciones consensuadas en casos controvertidos y la localización de adultos desaparecidos. Cada Estado contratante debe designar una Autoridad Central para cumplir con las obligaciones impuestas por el Convenio, que tienen como objetivo principal permitir la comunicación efectiva y la asistencia mutua entre los Estados partes.

Ahora bien, al consultar sobre la situación actual en cuanto a la cantidad de ratificaciones, el resultado no es muy auspicioso: a la fecha solo cuenta con 13 Partes contratantes. Esto motivó que algunos lleguen a sostener de modo tajante el fracaso del convenio. Otros, contrariamente, mantienen la fe en él argumentando que el escaso número de ratificaciones no debe poner en duda la calidad del instrumento (Muñoz Fernández, 2020, p. 1105). En este sentido, y para mantener una visión positiva, destacan que esta poca cantidad de ratificaciones se debe a la falta de conciencia sobre la importancia de esta realidad y el temor a asumir un nuevo compromiso. Adherimos a este razonamiento.

Es destacable que la Conferencia de La Haya se ha preocupado especialmente por el seguimiento e implementación de este convenio.

Entre otras iniciativas, sobresale la Conferencia conjunta CE-HCCH sobre la protección transfronteriza de los adultos vulnerables, celebrada en Bruselas, del 5 al 7 de diciembre de 2018. Fue organizada por la Comisión Europea y la 
Conferencia de La Haya, y concurrieron expertos de varios Estados, entre ellos Argentina, para debatir sobre esta peculiar temática.

Dentro de las principales conclusiones y recomendaciones destaca la invitación a los Estados que aún no son Partes a que evalúen la posibilidad y las ventajas de convertirse en Partes del mismo. Asimismo, se confirmó nuevamente que este Convenio es complementario de la Convención sobre los Derechos de las Personas con Discapacidad de Naciones Unidas.

Al tiempo que destacaron la utilidad práctica del Convenio en general, algunas Partes Contratantes mencionaron también que serían bienvenidas otras mejoras prácticas, en particular en lo que respecta a la aplicabilidad de las medidas (por ejemplo, guías de buenas prácticas, modelos de formularios y comunicaciones judiciales directas).

Señalaron que el reconocimiento transfronterizo de las medidas adoptadas en el marco del Convenio se vería reforzado por la elaboración de un perfil público de Estado para cada parte contratante que proporcione, por ejemplo, información sobre la naturaleza, los requisitos de fondo y de forma de las medidas adoptadas en el marco del Convenio, así como las condiciones de su entrada en vigor.

Asimismo, recomendaron para facilitar la circulación de los poderes de representación, el desarrollo y el uso de formularios modelo (o disposiciones modelo), certificados modelo de poder de representación y certificados modelo de acceso a los registros electrónicos para verificar su autenticidad e integridad, según lo establecido por las autoridades competentes.

También, en el marco de este Convenio, se destacó el potencial de las comunicaciones judiciales directas en el contexto de los adultos vulnerables.

Finalmente, se apoyó la iniciativa de la Oficina Permanente de la HCCH de solicitar la aprobación al Consejo de Asuntos Generales y Política de la Conferencia, para planificar y organizar una primera reunión de una Comisión Especial que revise el funcionamiento práctico del Convenio de Protección de Adultos de 2000.

Precisamente a tales fines, se han desarrollado unos cuestionarios dirigidos a los Estados como paso previo a la primera reunión de la Comisión Especial prevista para el año 2022.

\section{Notas desde el Derecho Internacional Privado argentino}

El actual marco jurídico argentino respecto de la protección transfronteriza de los adultos vulnerables se caracteriza por ser insuficiente y conformado por un 
mosaico de disposiciones complejas que incluyen desde tratados de DDHH hasta algunas pocas normas locales.

En agosto de 2015, el sistema de DIPr local fue objeto de una profunda y trascendental reforma que afectó los distintos sectores de esta disciplina, como aconteció con prácticamente todo el sistema jurídico en materia civil y comercial. Entre los cambios más sustanciales, reguló aspectos y temas que antes carecían de un autónomo reconocimiento a nivel local, como muchos de los temas referidos a la persona o a los niños, niñas y adolescentes. Además, logró modernizar varias de las disposiciones contenidas en el Código de Civil de Vélez Sarsfield (y sus posteriores reformas), acercando el derecho al modo en que el mundo actual se desenvuelve.

Pese a ello, aún encontramos temas en los cuales se mantiene una carencia, situación que nos pone ante una gran inseguridad jurídica. Ello no implica cuestionar las soluciones brindadas por la reforma, en la mayor parte de los casos resultaban absolutamente necesarias volviendo la labor de los legisladores encomiable y muy oportuna. Sin embargo, no puede considerarse que el trabajo se encuentra finalizado, todo lo contrario.

En lo que respecta a la protección de los adultos vulnerables, aún encontramos una lenta y casi omisa regulación. De allí que abogamos por una reforma que permita superar esta carencia de medidas de protección flexibles y adaptadas. Asentado ello, en este apartado analizaremos la respuesta que nuestra legislación hoy otorga en sus dos dimensiones: convencional e interna.

\section{VI.1. La fuente convencional vigente en la República Argentina}

Argentina no cuenta con normas convencionales específicamente destinadas a la protección internacional de adultos. Sin embargo, los célebres Tratados de Montevideo de Derecho Civil Internacional, tanto de 1889 como de 1940, contienen disposiciones referidas al instituto de la tutela y curatela. Estos convenios regulan tanto la jurisdicción como el derecho aplicable.

En cuanto a la determinación de la competencia, el Tratado de Montevideo de 1889 dispone en el artículo 59 que las acciones deben entablarse en el país en que estén domiciliados los tutores o curadores en todo lo que les afecte personalmente. La simple lectura de la norma hoy nos resulta injusta, y es correcto que así sea. Sin embargo, recordemos que su redacción responde al momento histórico y cultural en que fue creada, pero su lectura y la incidencia de los DDHH nos conduce a cuestionar la razonabilidad del contacto jurisdiccional. Cuando las acciones versen sobre la propiedad, enajenación o actos que afecten los bienes de los incapaces, deben ser deducidas ante los jueces del lugar en que esos bienes se hallan 
situados (artículo 60). Por su parte, el TM1940 no cuenta con las mismas normas, algo que no es muy común ya que, en general, se mantienen prácticamente las soluciones con pequeños cambios. Ante la falta de normas específicas, corresponde acudir a la norma general del artículo 56, que recepta el clásico paralelismo resultando la competencia de los jueces de lugar a cuya ley está sujeto el acto jurídico materia de juicio.

Respecto al derecho aplicable, ambos textos someten el discernimiento a la ley del lugar del domicilio de los incapaces (artículos 19 y 25), debiendo recordarse las calificaciones autárquicas que poseen para la determinación de este punto de conexión. Determinado el cargo de tutor o curador, esté será reconocido en los Estados parte (artículos 20 y 26). La diferencia en la regulación la vamos a encontrar respecto a los derechos y obligaciones que se generan de estos institutos. Mientras que la versión de 1889 las somete a la ley del lugar en que fue discernido el cargo (artículo 21), conexión nuevamente cuestionable por los mismos argumentos, en 1940 se optó por la ley del domicilio de los incapaces. Cierra la regulación del tema con las medidas urgentes disponiéndose que se rigen por la ley del lugar en que residen los tutores y curadores (artículos 24 y 30).

Finalmente, debemos recordar que existen varios tratados internacionales destinados a la cooperación jurídica internacional vigentes para nuestro país, que, aunque de alcance general, corresponde su aplicación en resguardo de los derechos de las personas adultas.

\section{VI.2. El Código Civil y Comercial de la Nación}

En este apartado abordaremos única y exclusivamente la regulación receptada por el CCiv. y Com. en cuanto a las disposiciones de DIPr, dejando por fuera aquella regulación que exista para los casos domésticos.

Como ya se mencionó, nuestro sistema no reconoce a la "protección de adultos" como una institución autónoma. Esto implica decir que no encontraremos un tratamiento especial dentro de las disposiciones de la parte especial que van desde el artículo 2613 al 2671. Sin embargo, dentro de la Sección $7^{\circ}$ se regula la "Responsabilidad parental e instituciones de protección" bajo la cual puede subsumirse el tema. Veamos.

\section{VI.2.1. La jurisdicción internacional}

La característica en estos casos es que estamos ante procesos calificados como jurisdicción voluntaria. Desde la mirada del DIPr argentino, este tipo de jurisdicción no cuenta con un gran desarrollo en la doctrina local. 
Un primer inconveniente, compartido con la responsabilidad parental, reside en la carencia de una norma de jurisdicción internacional propia. Desde la vigencia del texto la doctrina tomó nota de esta omisión debiendo asumir la labor de tener que pensar una solución para colmar el vacío(3).

En este sentido, una primera posibilidad se encuentra en reconocer la jurisdicción de las autoridades del país donde la persona adulta tenga su domicilio o residencia habitual, manteniendo así la postura en favor del criterio personal como sucede en todo el Código.

Para justificar esta elección, se argumenta que las autoridades de ese país son quienes están en una mejor posición al momento de evaluar la situación del adulto vulnerable por la cercanía física existente. Recordemos que, en este punto, se cuenta con la calificación autárquica (artículo 2615) la cual nos permite conocer qué debe entenderse por domicilio.

Resulta importante señalar que, cuando se trate de refugiados, de desplazados internacionalmente o de adultos cuya residencia habitual no puede establecerse, la competencia debería determinarse en función de país en dónde se encuentran, tal como lo propone el artículo 6 del Convenio de La Haya de 2000.

Otra forma de arribar a esta solución nos lleva a acudir a la interpretación del artículo 2641. Si bien la norma está destinada a determinar el derecho aplicable para el supuesto de medidas urgentes de protección, se establece en su parte final "sin perjuicio de la obligación de poner el hecho en conocimiento del Ministerio Público y, en su caso, de las autoridades competentes del domicilio o de la nacionalidad de la persona afectada". Entonces, puede entenderse que las autoridades del domicilio o de la nacionalidad del adulto cuentan con la competencia general. Esta línea de pensamiento mantiene - en parte- una coherencia con el punto anterior. La norma debería tomarse como una jurisdicción concurrente y su aplicación solo se justifica por la existencia de una situación de emergencia.

Sumado a este criterio, la existencia de bienes (tanto muebles como inmuebles) en nuestro país también presenta la razonabilidad suficiente para determinar la competencia de las autoridades del país dónde estos se encuentren, más no de manera exclusiva sino concurrente.

A todos estos criterios, debe sumarse el foro de necesidad de conformidad con lo regulado en el artículo 2602. Quizás encontrar algún supuesto que sea "contacto suficiente" por fuera del domicilio, residencia o lugar de situación de los bienes se vuelva complejo, pero su inclusión es sumamente importante. Ante la ausencia de

(3) Puede profundizarse en Baltar y Scotti (2019). 


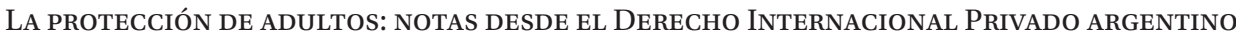

- LUCIANA B. SCOTTI Y LEANDRO BALTAR (PP. 427-456)

norma específica, hoy es la manera adecuada y justa para que nuestras autoridades puedan asumir la competencia ante el vacío que tenemos, siempre respetándose los preceptos que la norma exige y en respeto del derecho a la tutela judicial efectiva.

Incorporar una norma con contactos jurisdiccionales concurrentes puede desencadenar en el llamado "conflictos de competencia positivos", es decir, que las autoridades judiciales de más de un país asuman la competencia para el dictado de alguna medida de protección, desconociendo que su par extranjero realizó similar acción. Aquí toma relevancia la litispendencia, instituto que se presenta como una herramienta procesal dispuesta por la legislación con la finalidad de evitar llevar adelante procedimientos judiciales que podrían considerarse innecesarios (Baltar, 2019, p. 2). Hoy nuestro Código positivamente la regula en el artículo 2604.

Finalmente, corresponde expedirse respecto de la prórroga de jurisdicción. ¿Es factible el uso del acuerdo de elección de foro conforme lo recepta el artículo 2605? El debate se abre al momento de analizar literalmente los términos de la norma en la cual no se encuentra la "exclusividad" del contenido patrimonial como requisito. En nuestro parecer, consideramos que sería una herramienta discutible por los peligros susceptibles de configurarse. Si bien la posibilidad de elegir las autoridades jurisdiccionales otorga grandes beneficios en otras materias, en este caso debe optarse por soluciones protectoras. La presencia de una parte débil es el argumento principal para limitar el ejercicio de la autonomía de la voluntad, sin importar el posible contenido patrimonial que esté en juego.

En resumen, dotar a la autoridad del domicilio o residencia habitual de competencia implica mantener el foro razonable que históricamente se recepta como contacto jurisdiccional general. Concurrentemente, el foro del patrimonio se abre como posibilidad pues habitualmente las medidas a tomarse se dan en el mismo país dónde estos se encuentran.

Punto aparte, sobre lo cual no nos explayaremos simplemente lo dejamos planteado, es la posibilidad de acudir al controvertido forum non conveniens. Conforme esta teoría, un juez puede desconocer la competencia que le otorgó la norma por la de un tribunal de otro Estado si entiende que aquel tiene una vinculación más razonable y conveniente que él. Nuestro sistema no recepta una norma semejante.

\section{VI.2.2. La determinación del derecho aplicable}

El análisis del derecho aplicable, a diferencia de lo que sucede con la jurisdicción internacional, presenta otro escenario. Positivamente, vamos a encontrar regulado este aspecto, aunque no quizás del modo más acorde a la problemática. 
El artículo 2640 dispone como derecho aplicable a las instituciones de protección la ley del domicilio de la persona de cuya protección se trate al momento de los hechos que den lugar a la determinación del tutor o curador. De conformidad al tipo legal, todo lo referido al instituto de protección queda sometido a este derecho. Desde la causa y efectos de la incapacitación, quienes pueden solicitar las medidas de protección y quienes podrán ejercer la representación pasando por el contenido y alcance del cuidado y llegando hasta el fin de la medida (Uriondo de Martinoli, 2017, p. 253). Equiparándose la regulación de la tutela y la curatela, se considera que la solución implica una construcción que conduce entonces a la aplicación de una ley previsible (Dreyzin de Klor, 2017, p. 63). En coincidencia, calificada doctrina extranjera entiende que implica estar ante una conexión realista y construida sobre el principio de proximidad pues representa una vinculación clara, real, sustancial entre el sujeto y el país cuya ley resulta aplicable (Calvo Caravaca y Carrascosa González, 2018, p. 34).

La norma resuelve el problema del conflicto móvil, pues el domicilio que se tendrá en cuenta será el que se poseía al momento de los hechos que dieron lugar a la determinación del tutor o curador. Dicha fijación temporal y espacial del punto de conexión permite evitar las posibles configuraciones de fraudes que puedan perjudicar a los intereses del adulto. Si bien la técnica utilizada reduce los peligros típicos de la norma de conflicto, ello no implica que pueda resultar contraproducente.

En aquellos supuestos cuando el juzgador deba analizar las medidas de protección a tomar y el adulto vulnerable tiene un domicilio o residencia habitual distinto al que poseía al momento que nuestra norma indica, podría resultar una solución limitativa. Si la directriz a seguir se centra en el interés superior del adulto, sería correcto una flexibilización en la solución incorporando, como señalamos anteriormente, una materialización o seguir la línea tal como está receptada en el artículo 2639 al permitirse tomar en consideración "el derecho de otro Estado con el cual la situación tenga vínculos relevantes". Teniendo en cuenta la posible existencia de bienes, podría sumarse el derecho del país dónde estos se encuentren aplicando el más satisfactorio a los intereses del adulto.

La falta de una específica flexibilización no impide que podamos acceder igualmente a ella. Recordemos que resulta de aplicación la norma general receptada en el artículo 2597. Gracias a este recurso, se puede mejorar el funcionamiento del método conflictual al poder desplazar el derecho indicado por la norma indirecta y aplicar otro derecho con el que la situación jurídica internacional presente vínculos más estrechos (Scotti, 2019).

Otras legislaciones encontraron un modo distinto y especial para enfrentar el problema del conflicto móvil. El legislador español, luego de optar por la ley de la 
LA PROTECCIÓN DE ADULTOS: NOTAS DESDE EL DERECHO INTERNACIONAL PRIVADO ARGENTINO - LUCIANA B. SCOTTI Y LEANDRo BALTAR (PP. 427-456)

residencia habitual, entendió que ante su cambio se debía aplicar la nueva residencia, sin perjuicio del reconocimiento en ese país de las medidas de protección acordadas en otros Estados. De esta manera, y en la "sociedad líquida y móvil del siglo XXI, esta regla especial fija de un modo dinámico la ley aplicable" (Calvo Caravaca y Carrascosa González, 2018, p. 34).

Avanzando con el análisis, la norma literalmente menciona las figuras del tutor y curador lo cual nos lleva a pensar: ¿quedan afuera otros institutos? Recordemos que incluso nuestro sistema interno reconoce la figura del "apoyo", que no puede asimilarse a ninguno de ellos. Quizás la técnica legislativa pueda repensarse buscando una solución más conforme con este instituto. En este sentido, puede tomarse como inspiración el artículo 9.6 del Código Civil español (modificado por la ley 26/2015) estableciéndose como aplicable a la protección de las personas mayores vulnerables el derecho de su domicilio o residencia habitual al momento de analizarse o requerirse la protección. Optando por esta técnica, y utilizando un concepto más amplio, se lograría cambiar a un resultado más útil que incluya toda institución de protección del sujeto mayor edad, incluyendo aquellas que sean desconocidas (Calvo Caravaca y Carrascosa González, 2018, p. 34).

Sirviéndose del pluralismo metodológico, el legislador optó por una novedosa incorporación que resulta una herramienta muy positiva. El artículo 2640 recepta, además de la clásica norma indirecta analizada, el método de reconocimiento. Anteriormente, durante la vigencia del Código derogado, no encontrábamos disposición similar. Gracias a esta norma, acudir a la "institución desconocida" no sería un camino correcto pues, por el contrario, impone el deber de reconocer localmente todo instituto válidamente constitutivo en el extranjero, pero inexistente en el país, siempre que se respeten algunas condiciones. Así entonces, cuando las personas se mudan de un país a otro, ya no se verían expuestas a problemas derivados de la pluralidad legislativa y a un posible desconocimiento de la institución jurídica por ser diferente. Esto, como la doctrina señala, permite evitar relaciones claudicantes contribuyendo a la seguridad jurídica (Uriondo de Martinoli, 2017, p. 254). Sin embargo, nos enfrentamos ante un nuevo problema: la norma se refiere a otros institutos de protección, pero solo de niños, niñas y adolescentes (4).

La interpretación y aplicación literal de la norma nos lleva a concluir su inaplicación cuando se trate de la protección sobre adultos. Sin embargo, ¿es justo este nivel de desprotección? ¿No debería ampliarse el reconocimiento del instituto de protección como garantía fundamental? Como el fin buscado es garantizar la

(4) Artículo 2640, 2º́ párrafo: “Otros institutos de protección de niños, niñas y adolescentes regularmente constituidos según el derecho extranjero aplicable, son reconocidos y despliegan sus efectos en el país, siempre que sean compatibles con los derechos fundamentales del niño" (el destacado nos pertenece). 
protección internacional de las personas adultas vulnerables, extender la norma y permitir el reconocimiento automático de las medidas de protección ordenadas en el extranjero es el camino más adecuado. En esta postura, compartida por la doctrina (Dreyzin de Klor, 2017, p. 64), es donde nos ubicamos.

Sin duda esta nueva lectura de la disposición permitiría el reconocimiento en nuestro país de institutos aquí no reconocidos, pero creados en pos de un beneficio o protección de estos sujetos. Por ejemplo, la doctrina menciona al trust anglosajón constituido en beneficio de menores y de personas con discapacidad (Vaquero López, 2016, p. 402). En sintonía con esto, el Convenio de La Haya del 2000 dispone en el artículo 22 expresamente que las medidas adoptadas por las autoridades de un Estado contratante serán reconocidas de pleno derecho en los demás Estados. Claramente hay excepciones, pues ningún derecho es absoluto. Entre ellos, el más conocido y esperable es el supuesto cuando el reconocimiento fuera manifiestamente contrario al orden público del Estado requerido, o fuera contrario a una disposición de la ley de dicho Estado que tenga carácter imperativo independientemente de la ley que sería aplicable en otro caso.

\section{VI.2.3. La cooperación jurídica internacional}

Una pieza clave para el Derecho Internacional Privado, y en particular para contribuir a la protección de personas vulnerables es la cooperación jurídica internacional. Sin bien, Argentina no ha ratificado el Convenio de La Haya de 2000 y, por ende, no cuenta con disposiciones específicas en el tema, como corolario del principio de acceso a la justicia, el artículo 2611 CCiv. y Com. erige a la cooperación jurisdiccional en sentido amplio, en un deber de los jueces nacionales.

En el ámbito del derecho civil y comercial de fuente interna, la República Argentina no había reconocido con anterioridad un deber general de cooperación internacional en cabeza de nuestros jueces.

De acuerdo con el artículo 2611, el deber de cooperación en materia civil, comercial y laboral se erige en un principio que solo podría denegarse en caso de ausencia de requisitos básicos exigibles para proceder a la cooperación solicitada o bien que la rogatoria afecte de manera grave y manifiesta algún principio fundamental de nuestro ordenamiento jurídico. Adviértase que la disposición es incondicional: no puede exigirse ningún tipo de reciprocidad de parte de las autoridades extranjeras.

Si bien la norma mencionada solo hace alusión a los jueces en cuanto a sujetos obligados por el mandato de la cooperación, la misma obligación recae sobre cualquier otra autoridad con un ámbito de competencia en materia civil, comercial o laboral a la cual una autoridad extranjera le solicita cooperación. 


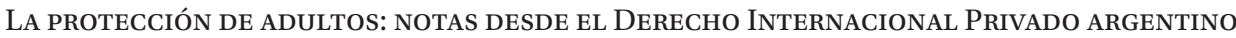
- LUCIANA B. SCOTTI Y LEANDRO BALTAR (PP. 427-456)

Téngase presente que el artículo 2611 se aplicará en defecto de disposiciones convencionales o bien con la finalidad de complementarlas. La República Argentina ha ratificado un número significativo de tratados internacionales en materia de cooperación jurisdiccional internacional en general o en materias específicas. Entre ellos, destacan el Protocolo de Las Leñas sobre Cooperación y Asistencia Jurisdiccional en Materia Civil, Comercial, Laboral y Administrativa, de 1992, vigente entre los Estados parte del Mercosur; la CIDIP I - Convención Interamericana sobre Exhortos o Cartas Rogatorias de 1975; la CIDIP II - Convención Interamericana sobre Ejecución de Medidas Preventivas de 1979; el Convenio de La Haya sobre la Notificación o Traslado en el Extranjero de Documentos Judiciales y extrajudiciales en Materia Civil o Comercial de 1965.

En suma, tal como disponen los Principios ASADIP sobre el Acceso Transnacional a la Justicia (Transjus), aprobados por la Asamblea de la Asociación Americana de Derecho Internacional Privado, en Buenos Aires, el 12 de noviembre de 2016, el derecho de acceso a la justicia impone a todos los Estados la obligación de cooperar jurídicamente en la realización de la justicia, más allá del plano meramente judicial, en cualquier situación que se vincule con jurisdicciones foráneas.

El principio in dubio pro cooperationis debe guiar a toda autoridad que tenga que intervenir o decidir en un conflicto que involucre derechos de sujetos especialmente vulnerables.

\section{Observaciones finales}

Las convenciones sobre DDHH receptan y regulan la protección respecto de las personas adultas, mencionamos en este sentido la existencia de tratados internacionales al respecto mediante la creación de disposiciones genéricas que abarcan a estos sujetos débiles. Sin embargo, estos instrumentos no son suficientes. Pensamos así, pues si bien proporcionan una orientación rica en principios fundamentales, no solo sus términos son fácilmente susceptibles de una interpretación disímil, sino que son insuficientes para resolver los problemas que se plantean en el ámbito del DIPr.

En efecto, el problema se encuentra en dos puntos. Encontramos una generalizada ausencia normativa que lacera los derechos a proteger. Al mismo tiempo, entre los pocos países en los cuales puede hallarse alguna disposición susceptible de ser aplicable, aparece el problema de la diversidad legislativa que pone en riesgo el objetivo de protección.

Así entonces, la situación es preocupante pues la carencia de una correcta protección a nivel internacional impide que puedan gozar de sus derechos, situación mucho más compleja cuando estos sujetos se desplazan de un país a otro no pudiendo 
tener la seguridad jurídica de que gozarán del debido cuidado. No cabe duda que la inserción de esta categoría de protección sobre estos sujetos implica un respeto al derecho de la identidad de las personas, alcanzadas por situaciones contempladas en diversos ordenamientos en función de sus culturas (Dreyzin de Klor, 2017, p. 60).

La fuente convencional es la mejor dotada para regular las situaciones jurídicas transfronterizas que involucran a adultos vulnerables, en particular en lo que atañe al sector de la cooperación jurídica internacional.

En tal sentido, debe encararse un análisis serio del Convenio de La Haya, difundir sus alcances y ventajas, así como estudiar el impacto e implementación en los Estados que lo han ratificado.

Por otro lado, y ante el poco interés de los Estados en dicho Convenio multilateral, sería prudente y sumamente positivo que el Mercosur, como foro de codificación, analice incluir el tema en su agenda. Teniendo en cuenta las libertades que pretende garantizar, involucrarse en esta problemática facilitaría la circulación transfronteriza de los adultos entre los Estados parte. Como sostiene Franzina: "Un enfoque regional uniforme respecto a esta materia incrementaría la seguridad jurídica y permitiría a los individuos interesados planificar sus vidas de forma eficiente, sin el temor de experimentar una laguna en su protección (o de tener que iniciar procedimientos de protección desde cero) cada vez que decidan disfrutar de la libertad consagrada en los Tratados" (2016, p. 138).

Desde la mirada interna, la legislación local se encuentra en una situación similar. Vimos como la falta de normas especiales se traduce en una deuda sobre la cual es menester trabajar y a la mayor brevedad.

A la ausencia de normas específicas para la determinación de la jurisdicción internacional como para el derecho aplicable, encontramos una falta de normativa que garantice el reconocimiento mutuo y la ejecución de las medidas de protección dictadas en el extranjero y en relación con el adulto vulnerable. Para solucionar ello, se acude a la ampliación y adaptación de los artículos analizados, como único modo de evitar la desventaja del sistema actual.

En resumen, la protección internacional de las personas adultas requiere de la adopción de normas específicas que impongan obligaciones jurídicamente vinculantes en todos los sectores del DIPr. Solo de este modo podrá considerarse cumplida las directrices plasmadas en los convenios de DDHH al respecto y se podrá crear un verdadero sistema de DIPr en materia de protección de adultos.

De todo lo expuesto, se llega a concluir que no existe un marco jurídico que establezca una protección efectiva para los adultos vulnerables en casos transfronterizos. 
Ante ello, la adopción de normas de DIPr que aborden los cuatros sectores en un solo texto, teniendo de modelo el éxito indiscutido alcanzado en materia de niños, niñas y adolescentes, sin perjuicio de las adaptaciones necesarias, contribuirá a la protección integral de este grupo de personas.

Posiblemente, en algunos años, cuando las sociedades nacionales, así como la comunidad internacional, tomen real consciencia de la situación que atraviesan muchos adultos especialmente vulnerables, podamos referirnos a un verdadero cambio de paradigma, a partir de la consolidación de un sistema de protección internacional e integral de los adultos.

\section{Bibliografía}

Adroher Biosca, S. (2019). La protección de adultos en el Derecho Internacional Privado español: novedades y retos. Revista Española de Derecho Internacional, Vol. 71/1, enero-junio (pp. 163-185).

Álvarez Torne, M. (2016). Current issues in the protection of adults from the perspective of private international law. Revista Electrónica de Estudios Internacionales, № 32 (pp. 1-18). Recuperado de http://www.reei.org/ [Fecha de consulta: $12 / 02 / 2021]$.

Baltar, L. (2019). La litispendencia internacional y su regulación en el Código Civil y Comercial de la Nación. El Derecho, № 14.601, Año LVII (pp. 1-5).

Baltar, L. y Scotti, L. B. (2019). La jurisdicción internacional directa en un caso de responsabilidad parental. El Derecho, año LVII. ED 283.

Borda, G. J. (2017). Derecho Civil. Parte General. Buenos Aires: La Ley.

Borrás Rodríguez, A. (2000). Una nueva etapa en la protección internacional de adultos. Revista Electrónica de Geriatría, Vol. 2, № 1.

Calvo Caravaca, A. L. y Carrascosa González, J. (2018). Derecho Internacional Privado, Vol. II. Granada: Ed. Comares.

De Araujo, N. (2016). Derecho internacional privado: teoría y práctica brasileña. E Book Revolution.

Dreyzin de Klor, A. (2017). El Derecho internacional privado actual, Tomo II. Buenos Aires: Ed. Zavalía. 
Duran Ayago, A. (2002). Aproximación la Protección de los Incapaces en el Derecho Internacional Privado Italiano. Anuario de la Facultad de Derecho Universidad de Extremadura (AFDUE), № 19 (pp. 363-380).

Fernández Oliva, M. (2015). La tutela de la vejez en el marco del Derecho Internacional Privado: convenio de La Haya de 13 de enero de 2000, sobre la protección internacional de los adultos. Revista Investigación y Docencia (pp. 69-80).

Franzina, P. (2016). La protección internacional de adultos vulnerables: un llamamiento a la acción a nivel de la Unión Europea. Anuario Español de Derecho Internacional Privado, T XVI (pp. 127-145).

Fulchiron, H. (2017). Acerca de la vulnerabilidad y de las personas vulnerables. Tratado de la Vulnerabilidad. Buenos Aires: La Ley.

Lagarde, P. (2017). Convenio de 13 de enero de 2000 sobre Protección Internacional de los Adultos. Conferencia de La Haya de Derecho Internacional Privado. Recuperado de www.hcch.net

Lagarde, P. (2000). La convention de La Haye du 1 janvier 2000 sur la protection international de adultes. Revue critique de Droit International Privé, Dalloz, No 89 (2) (pp. 159-179).

Lagarde, P. (dir.) (2011). La Reconnaissance des situations en droit international privé. La Haya: Ed. Pedone.

Long, J. (2013). Rethinking vulnerable adults' protection in the ligth of the 2000 Hague Convention. International Journal of Law, Policy and the Family, № 27 (pp. 51-73).

Muñoz Fernández, A. (2020). Notas sobre el informe del Instituto de Derecho Europeo acerca de la protección de adultos en situaciones internacionales. Cuadernos de Derecho Transnacional, Vol. 12, № 2 (pp. 1099-1105).

Schwenzer, I. y Keller, T. (2013). A new law for the protection of adults. The international survey of family law (pp. 375-386).

Scotti, L. B. (2019). Manual de Derecho Internacional Privado. Buenos Aires: Ed. La Ley.

Scotti, L. B. (2020). Flexibilización y cláusula de excepción en el Derecho Internacional Privado argentino. Ratio Iuris. Revista de Derecho Privado, Año VIII, No 2 (pp. 261-291). Recuperado de https://publicacionescientificas.uces.edu.ar/index. $\mathrm{php} / \mathrm{ratioiurisB/article/view/1104} \mathrm{[Fecha} \mathrm{de} \mathrm{consulta:} \mathrm{08/09/2021].}$ 
Uriondo de Martinoli, A. (2017). Lecciones de Derecho Internacional Privado: Relaciones de Familia, Código Civil y Comercial de la Nación. Córdoba: Ed. Lerner.

Vaquero López, C. (2016). Nuevas normas de Derecho Internacional Privado en materia de protección de adultos y de menores. Anuario Español de Derecho Internacional Privado (pp. 395-414).

Fecha de recepción: 04-03-2021 Fecha de aceptación: 09-09-2021 
